\title{
Ação do fungo predador de nematóides Arthrobotrys conoides sobre larvas infectantes de Cooperia punctata
}

\section{Effect of the nematode-trapping fungus Arthrobotrys conoides on infective larvae of Cooperia punctata}

\author{
Jackson Victor de Araújo, * Marcos Pezzi Guimarães**
}

\begin{abstract}
Resumo
Em ensaios in vitro testou-se a capacidade predatória do fungo Arthrobotrys conoides sobre larvas infectantes (L3) de Cooperia punctata e à microscopia eletrônica de varredura observou-se esta interação. Para tanto, formaram-se dois grupos, cada um com seis repetições: um grupo tratado, 1.000 conídios de $A$. conoides e 10.000 L3 de C. punctata e um grupo controle, 10.000 L3 de C. punctata. Diariamente, por 10 dias, as placas dos dois grupos foram observadas ao microscópio óptico, sendo quantificados os números de larvas livres de captura pelo fungo. A comparação entre as médias de larvas não capturadas demonstrou que $A$. conoides foi eficaz na predação das larvas de $C$. punctata $(P<0,01)$. No ensaio de microscopia eletrônica de varredura, a metodologia utilizada foi eficiente e pode ser empregada em posteriores estudos para verificar a interação dos fungos com os nematóides.
\end{abstract}

Palavras-chave: controle biológico; fungos nematófagos; fungos predadores de nematóides; microscopia eletrônica de varredura; Arthrobotrys conoides; Cooperia punctata.

\begin{abstract}
An in vitro assay was performed to test the predatory activity of nematode-trapping fungus Arthrobotrys conoides against Cooperia punctata larvae (L3) and the scanning electron microscope assay was performed in order to observe the interaction between L3 and the fungus. Two groups with six repetitions were formed: treated group, 1,000 conidia of $A$. conoides and 10,000 L3 and control group, 10,000 L3. Daily, for 10 days, on the dishes from the groups were examined under an optic microscope and the number of freely migrating larvae counted. Comparison between means of freely $L 3$ in the presence of fungus show $A$. conoides was effective in the control of $C$. punctata. The scanning electron microscope assay was satisfactory and could be used in future studies involving interaction between nematode-trapping fungus and nematodes.
\end{abstract}

Keywords: Biological control; nematophagous fungi; nematode-trapping fungi; scanning electron microscope; Arthrobotrys conoides; Cooperia punctata.

\section{Introdução}

O controle biológiço, mediante o uso de microrganismos, é alternativa promissora no controle de nematóides. Organismos como fungos, bactérias, vírus, protozoários, e tardígrados, entre outros, têm sido identificados como parasitas ou predadores de nematóides (Van Gundy, 1985).

De acordo com Araújo (1999), os fungos antagonistas de nematóides podem ser divididos em predadores, endoparasitas, oportunistas (parasitos de ovos e de fêmeas parasitas de plantas) e produtores de metabólitos tóxicos aos nematóides.

Os fungos predadores de estádios de vida livre dos nematóides parasitos de animais domésticos são vastamente encontrados na natureza, ocorrendo em plantas, em esterco e no solo (Hashmi e Connan, 1989). Segundo Balan e Gerber (1972), eles formam armadilhas que são produzidas a intervalos ao longo da hifa e em cultura pura; muitos desses fungos não formam armadilhas. Além disso, a formação dessas estruturas é resposta à presença de nematóides ou de substâncias deles derivadas, ou ainda a vários outros compostos de origem biológica. Também são induzidas por condições adversas de cultivo, como escassez de água e/ou de nutrientes (Balan e Gerber, 1972). Após a captura, independentemente da armadilha utilizada, o fungo penetra e se desenvolve no interior do nematóide, consumindo o seu conteúdo e lançando para o meio externo as suas estruturas vegetativas e reprodutivas (Barron, 1977 e Gray, 1987).

O presente trabalho teve por objetivo avaliar a eficácia do fungo predador de nematóides Arthrobotrys conoides no contro-

\footnotetext{
* Departamento de Veterinária, Universidade Federal de Viçosa, CEP 36571-000, Viçosa-MG, E-mail: jvictor@mail.ufv.br

** Departamento de Parasitologia, Universidade Federal de Minas Gerais, CEP 31270-901, Belo Horizonte-MG, E-mail: pezzi@mono.icb.ufmg.br
} 
le de larvas infectantes de Cooperia punctata em condições de laboratório e observar esta interação à microscopia eletrônica de varredura.

\section{Material e métodos}

\section{Eficácia sobre larvas infectantes de Cooperia punctata (Araújo et al., 1993)}

Um isolado do fungo predador de nematóides Arthrobotrys conoides mantido em tubos de ensaio, contendo meio de cultura Batata Dextrose Ágar (BDA $2 \%$ ), a $4^{\circ} \mathrm{C}$ e no escuro, foi utilizado para avaliar a eficácia sobre larvas infectantes (L3) de Cooperia punctata, em condições de laboratório. Para induzir à produção de conídios e armadilhas deste isolado fúngico, discos de cultura de aproximadamente $5 \mathrm{~mm}$ de diâmetro do fungo foram transferidos para placas de Petri de $15 \mathrm{~cm}$ de diâmetro, contendo ágar-água (AA $2 \%$ ), a $25^{\circ} \mathrm{C}$. A estas placas foram adicionados, de dois em dois dias, $2 \mathrm{ml}$ de suspensão com 1.000 Panagrellus $s p$, por um periodo de 14 dias, até que a superfície das placas fosse completamente preenchida pelo fungo. Após dois dias da última aplicação de Panagrellus $s p, 5 \mathrm{ml}$ de água destilada foram adicionados a cada placa de Petri e, com a ajuda de um pincel, os conídios e fragmentos de micélio foram removidos e estocados em pequenos frascos, a $4^{\circ} \mathrm{C}$.

Para se estudar a atividade predatória do fungo $A$. conoides sobre $L 3$ de $C$. punctata, formaram-se dois grupos; um grupo tratado, constituído por 1.000 conídios e 10.000 L3 e um grupo controle com 10.000 L3. Em cada grupo foram feitas seis repetições.

$O$ fungo e as larvas infectantes foram transferidos para placas de Petri de $8,5 \mathrm{~cm}$ de diâmetro, contendo meio AA $2 \%$ e, previamente, marcados com perfuradores de ágar, formando, sobre a superfície, campos de $4 \mathrm{~mm}$ de diâmetro.

As placas de Petri foram mantidas à temperatura de $25^{\circ} \mathrm{C}$ e no escuro. Diariamente, por um período de 10 dias, as placas dos dois grupos foram observadas ao microscópio óptico (objetivas de 10 e 20x), escolhendo-se, aleatoriamente, dez campos, sendo tomado o número de larvas infectantes livres de predação ou captura pelos fungos. $O$ número de $L 3$ livres foi convertido em média por campo de $4 \mathrm{~mm}$ de diâmetro e, posteriormente, tomada a média de seis repetições. A eficiência da predação exercida pelos fungos sobre as $L 3$ foi realizada, comparando as médias obtidas dos grupos pelo teste $T$ de student $(P<0,01)$.

\section{Microscopia eletrônica de varredura (Nordbring-Hertz, 1983 e Guimarães e Caldeira, 1997)}

Discos de cultura de $A$. conoides foram removidos para placas de Petri de $8,5 \mathrm{~cm}$ de diâmetro, contendo $20 \mathrm{ml}$ de BDA $2 \%$ e sobre estas uma membrana de diálise com 20.000 de porosidade. As placas foram incubadas, no escuro, à temperatura de $25^{\circ} \mathrm{C}$, por sete dias. A seguir, aproximadamente 1.000 larvas infectantes de $C$. punctata foram vertidas sobre as membranas nas placas. Após 48 horas, as membranas foram retiradas e fixadas em glutaraldeído $6 \%$ em tampão cacodilato de sódio pH 7,2 por 24 horas, lavadas seis vezes no tampão, pós-fixadas em tetróxido de ósmio $2 \%$, lavadas novamente por seis vezes e desidratadas em uma série de álcool etílico. As membranas foram secas em secador de ponto crítico utilizando dióxido de carbono, recobertas com ouro e fotografadas em microscópio eletrônico de varredura Zeiss a $10 \mathrm{kV}$.

\section{Resultados e discussão}

Na Figura 1 estão representados os valores médios diários de larvas infectantes de Cooperia punctata livres no ágar por campo de $4 \mathrm{~mm}$ de diâmetro nas placas dos grupos tratado e controle. Houve diferença estatisticamente significativa $(P<0,01)$ entre os valores coletados dos dois grupos. Isto indica que $A$. conoides foi eficaz no controle biológico de larvas infectantes de $C$. punctata in vitro. Observou-se, também, que logo no primeiro dia após o início do ensaio, as larvas infectantes livres nas placas do grupo tratado foram menores que as do grupo controle, sendo notada maior diferença a partir do sexto dia. Segundo Pramer (1964), a diferenciação da hifa pode ocorrer dentro de 24 horas e numerosas estruturas de captura serem produzidas. Além disso, notou-se um leve declínio destes valores, com o passar dos dias, nas placas do grupo controle, sendo que algumas larvas infectantes de $C$. punctata morreram sem a presença dos fungos predadores, e algumas delas migraram para a periferia das placas de Petri.

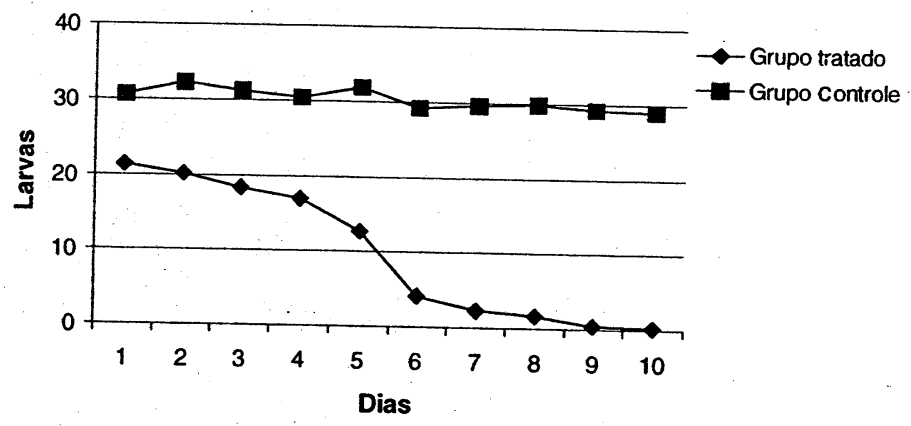

Figura 1: Número de larvas infectantes de Cooperia punctata livres por campo de $4 \mathrm{~mm}$ de diâmetro nas placas de Petri do grupo tratado com o fungo Arthrobotrys conoides e grupo controle, durante 10 dias.

Em experimentos in vitro, a ausência de qualquer competidor e a falta de uma fonte alimentar alternativa no agar podem forçar os fungos a utilizarem os nematóides como a única fonte alimentar disponivel. No presente trabalho, a presença das larvas infectantes de $C$. punctata foi fundamental para a formação de armadilhas, tendo esse fungo utilizado as larvas como fonte de nutrientes.

Outros trabalhos in vitro com este mesmo isolado sobre larvas infectantes de Haemonchus placei (Araújo et al., 1993) e de $H$. contortus (Mota et al., 2000) juntamente com o presente trabalho confirmam a eficácia deste isolado fúngico sobre larvas infectantes de nematóides parasitos de animais domésticos.

Na Figura 2 está representada a captura das larvas infectantes de $C$. punctata por $A$. conoides ao microscópio eletrônico de varredura. As micrografias apresentaram boa resolução e demonstraram que a metodologia utilizada foi eficiente e pode ser empregada em posteriores ensaios. Nestas micrografias nota-se, também, o desenvolvimento das hifas sobre os nematóides. 

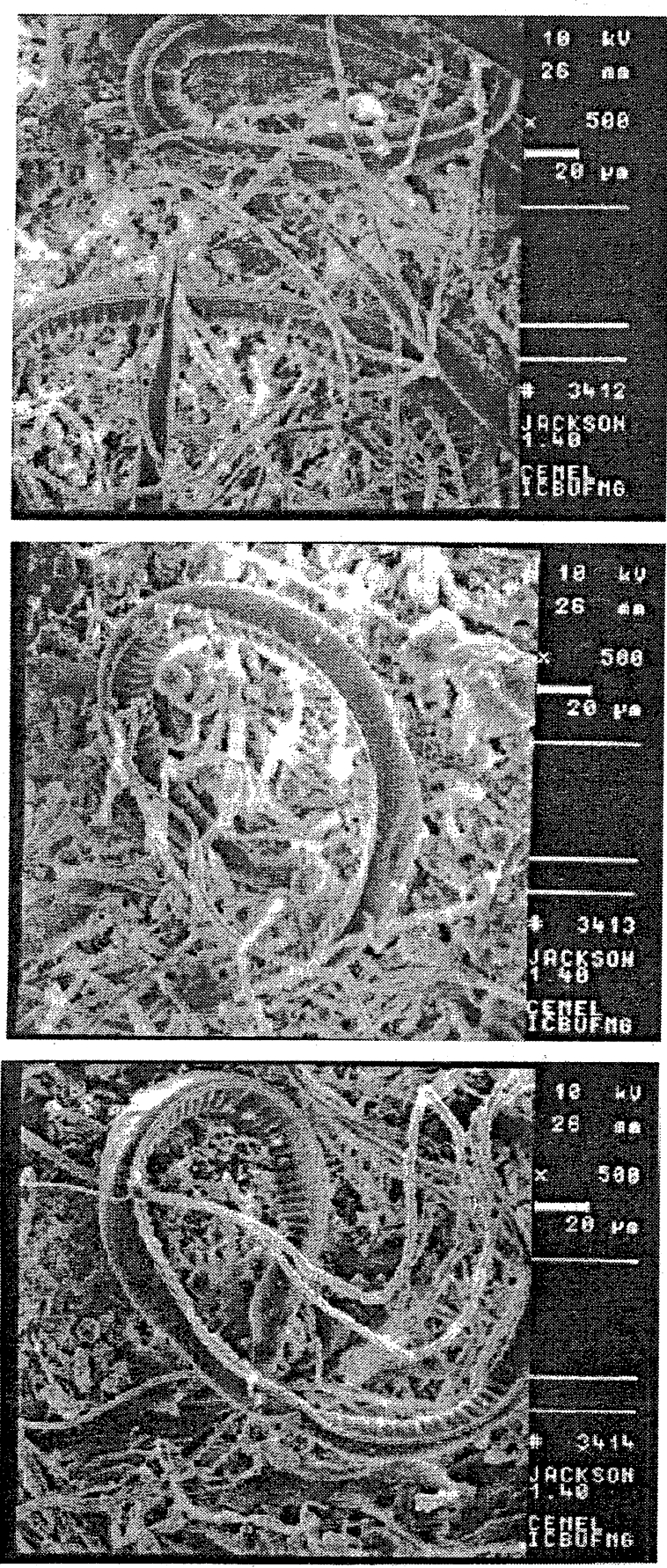

Figura 2: Micrografias eletrônicas de varredura da interação de larvas infectantes de Cooperia punctata com o fungo predador de nematóides Arthrobotrys conoides (aumento de 500x).
Uma forma promissora de utilização prática dos fungos nematófagos no controle biológico seria a formulação do fungo. Salgado e Campos (1993) realizaram a formulação do fungo $A$. conoides em matriz de alginato de sódio e evidenciaram que após oito semanas, esta formulação se manteve viável e eficiente quando testada sobre o nematóide de vida livre $P$. redivivus.

\section{Conclusões}

Com base nos resultados obtidos, pode-se concluir que:

- O fungo predador de nematóides Arthrobotrys conoides é um promissor agente para o controle biológico de larvas infectantes de Cooperia punctata.

- O ensaio de microscopia eletrônica de varredura pode, no futuro, ser empregado em estudos de interação de fungos nematófagos com nematóides.

\section{Referências}

ARAÚJO, J. V. Controle de nematóides parasitas de bovinos por fungos nematófagos. Uma nova alternativa. Cad. Téc. Vet. Zootec., v. 30, p. 75-88, 1999.

ARAÚJO, J. V., SANTOS, M.A., FERRAZ, S., MAIA, A. S. Antagonistic effect of Predacious Arthrobotrys fungi on infective Haemonchus placei larvae. J. Helminthol., v. 67, n. 2, p.136-138, 1993.

BALAN, J., GERBER, N. Attraction and killing of the nematode Panagrellus redivivus by the predacious fungus Arthrobotrys dactiloides. Nematologica, v. 18, n. 3, p.163-173, 1972

BARRON, G. L. (Ed.): The Nematode-Destroying Fungi. 1. ed. Guelph: Canadian Biological Publications, 1977.

GRAY, N. F. Nematophagous fungi with particular reference to their ecology. Biologic. R., v. 62, n. 4, p. 245-304, 1987.

GUIMARÃES, M. P., CALDEIRA, M. C. M. Scanning electron microscopy of Haemonchus similis (Nematoda:Trichostrongylidae) parasite of cattle. Rev.Bras.Parasitol.Vet., v. 6, n. 2, p.139-141, 1997.

HASHMI, H. A., CONNAN, R. M. Biological control of ruminant Trichostrongylids by Arthrobotrys oligospora, predacious fungus. Parasitol. Today, v. 5, n. 1, p. 28-30, 1989.

MOTA, M. A., BEVILAQUA, C. M. L., ARAÚJO, J. V. Atividade predatória dos fungos Arthrobotrys conoides e Monacrosporium thaumasium sobre larvas infectantes de Haemonchus contortus de caprinos. Ciência Animal, v. 10, n. 1, p. 37-41, 2000.

NORDBRING-HERTZ, B. Dialysis membrane technique for studying microbial interaction. Appl. Environ. Microbiol., v. 45, n. 1, p. 290-293, 1983.

PRAMER, D. Nematode-trapping fungi. Science, v.144, p. 382-388, 1964.

SALGADO, S. M. L., CAMPOS, V. P. Formulação do fungo Arthrobotrys conoides em alginato de sódio para o controle de nematóides. Nematol. Bras., v. 17, n. 2, p.140-151, 1993.

VAN GUNDY, S. D. Biological control of nematodes. In: HOY, M. A., HERZOG, D. C. (Ed.). Biological control in agricultural IPM systems. 1. ed. Maryland: CRC, 1985, p. 211-229. 